\title{
TrANSCRIÇÃo do VALE do AVE EM SOM: CRIAÇÃo DE UMA LINGUAGEM ESPÁCIO-SONORA
}

\author{
Cidália Ferreira Silva \& Eugénia Aguiar Leite
}

\begin{abstract}
RESUMO
A transcrição do Vale do Ave em som (Leite, 2014) surge do cruzamento da representação do território com a representação sonora, aplicada à interpretação de duas amostras do Vale do Ave - o centro de Guimarães e o "entre Brito e Silvares" -, através da criação de notações gráficas ambivalentes, que simultaneamente representam o espaço e o som. Neste artigo, apresenta-se o processo de transcrição criado, o qual tem como questão geradora: como transcrever o espaço urbano em som? Aquilo que tradicionalmente se denomina de paisagem sonora (Augusto, 2014; Schafer, 1993) reflete sobre o som existente nos lugares. Este artigo inverte esta proposição, pretendendo transcrever a espacialidade dos lugares em som. Assim neste contexto, o termo "ouvir" o território não se refere aos sons reproduzidos pelos carros, pelo vento, pelas folhas das árvores, etc., mas sim ao som resultante da composição espacial. Os resultados da investigação comprovaram o vínculo entre o espaço e o som, uma vez que a composição musical correspondente a cada amostra não só é distinta, como nos remete para a sua espacialidade, abrindo um campo interdisciplinar passível de novas interseções em outros lugares, com possibilidades mútuas de inovação tanto ao nível da composição espacial como da composição musical.
\end{abstract}

\section{Palavras-chave}

Gramática; som e espaço; transcrição; território

\begin{abstract}
The transcription of Vale do Ave into sound (Leite, 2014) emerges from the intersection of the visual display of both territory and sound, applied to the interpretation of two samples from Vale do Ave - the Guimarães city centre and the "between Brito and Silvares" - through the creation of ambivalent graphic notations, which simultaneously represent space and sound. This article presents the transcription process created in response to the question "how to transcribe urban space into sound?" What is traditionally called soundscape (Augusto, 2014; Schafer, 1993) reflects on the existing sounds in a given place. This article reverses this proposition and aims to transcribe spatiality into sound. So in this context, the term "listening to" the territory does not refer to the sounds produced by cars, wind, tree leaves, etc., but to the sound resulting from the spatial composition. The research results have proven the link between space and sound, since the musical composition corresponding to each sample is not only distinct, but also refers us to its spatiality, opening up an interdisciplinary field, subject to further intersections in other areas, with mutual possibilities of innovation in both spatial and musical composition.
\end{abstract}

\section{KeYwORDS}

Grammar; sound and space; territory; transcription 


\section{INTRODUÇÃO}

Esta investigação surge do cruzamento da representação do território com a representação sonora, enquanto ferramenta operativa de interpretação, através da interseção entre a música e a arquitetura enquanto campo expandido (Silva, 2011). Reconhecendo-se que tanto o som como o espaço são passíveis de representação gráfica, o processo de investigação gerou uma linguagem de interseção entre o espaço "real" de duas amostras do Vale do Ave e a composição sonora correspondente. Qual a sonoridade dos espaços de cada lugar? Como encontrar uma linguagem comum? A experimentação desenvolvida foi elaborada no sentido de dar resposta a estas questões, permitindo avançar com a investigação sobre a intersecção entre a representação da composição do território e a composição sonora, respetiva construção da metodologia de transcrição e estratégia. Estratégia esta que se aproximou tanto à compreensão dos vínculos "entre" espaço e som - sistematizados na linguagem explorada através da gramática e do abecedário de interseção criados -, como também no desdobramento do método de transcrição aplicado às amostras selecionadas.

Este artigo está estruturado em três partes fundamentais: (1) no estado da arte, faz-se o enquadramento desta pesquisa nas referências sobre o território do Vale do Ave, discutem-se os conceitos-chave relativos à paisagem sonora e exploram-se as referências pré-existentes que são relevantes para a conceção da metodologia de transcrição criada, nomeadamente investigando as possibilidades de representação gráfica mútua; (2) na metodologia, desenvolve-se a linguagem comum entre o espaço e o som através da sua aplicação a duas amostras do território do Vale do Ave com espacialidades distintas, com o objetivo de testar a existência de uma correspondência específica entre a composição espacial e composição sonora; (3) na análise dos resultados, discutem-se as sonoridades resultantes das duas amostras transcritas. Termina-se com a discussão das principais conclusões e perspetivas futuras de investigação.

As amostras escolhidas decorrem do reconhecimento da variabilidade morfológica do Vale Ave, caracterizado por dois modelos de povoamento': o modelo compacto e o modelo difuso (Silva, 2007, p. 4). Assim do tecido compacto do Vale do Ave, selecionou-se o centro de Guimarães ${ }^{2}$ (Figura 1), enquanto do tecido difuso se selecionou a amostra "entre Brito e Silvares"3 (Figura 2).

\footnotetext{
' Em trabalho anterior (Silva, 2007), explicámos que o Vale do Ave tem dois modelos de povoamento, a saber: o modelo compacto e o modelo difuso. O modelo compacto corresponde ao tecido urbano das sedes de concelho (Guimarães, Vila Nova de Famalicão, Santo Tirso, Vizela e Trofa) e o modelo difuso, corresponde ao tecido urbano 'entre' as sedes de concelho. A seleção das amostras para esta investigação resulta deste reconhecimento, garantindo não só a sua relevância para o aprofundamento do estudo deste território, como a possiblidade de criar uma linguagem que integra um leque mais diverso de morfologias urbanas, revelando consequentemente o seu potencial de aplicabilidade a outros lugares do urbano contemporâneo.

${ }^{2} \mathrm{O}$ tecido compacto do centro de Guimarães caracteriza-se essencialmente pela sua malha densa e hierarquizada, assim como pelas frentes edificadas contínuas a caracterizar o seu espaço público, nomeadamente, praças, ruas e jardins.

3 Em "entre Brito e Silvares" identificam-se as características preponderantes do tecido difuso, nomeadamente, o facto da edificação não ter a preponderância na ocupação do território. Esta é implantada numa rede infra-estrutural densa e resulta da proximidade e interdependência entre atividades - indústria, habitação com atividades complementares e agricultura -, as quais se apropriam dos recursos do território, nomeadamente da água e do solo, nas suas vocações específicas. A parcela tem uma capacidade generativa neste tecido urbano, sendo que o sistema de relações morfológicas no difuso é descrito pela articulação entre parcelas que se adaptam a distintos usos e apropriações.
} 


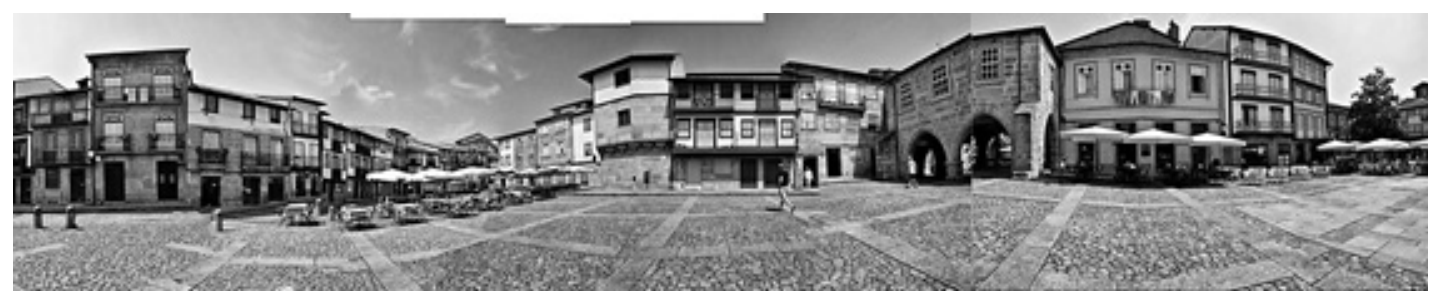

Figura 1: Praça de Santiago, Guimarães

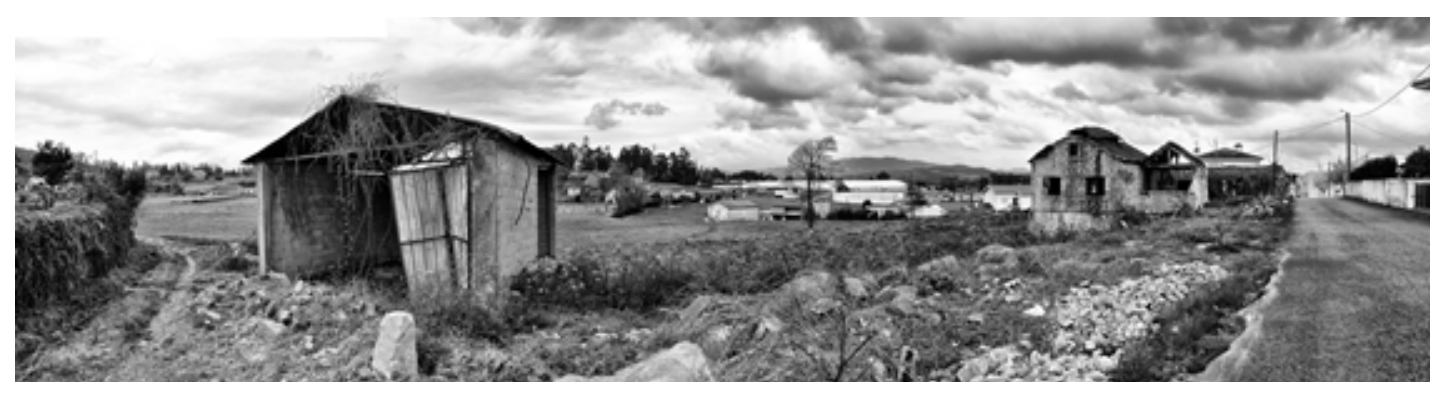

Figura 2: Rua do Couto, Brito

\section{ESTADO DA ARTE}

O presente estado da arte está desenvolvido em três partes. Em primeiro lugar, faz-se o enquadramento deste artigo na investigação existente sobre o território do Vale do Ave e discutem-se os conceitos-chave no âmbito do estudo da paisagem sonora; em segundo lugar, apresentam-se as referências gráficas do som que suportaram a notação gráfica criada; por último, exploram-se os exemplos que serviram de apoio ao desenho sonoro do espaço.

\section{ENQUADRAMENTO}

O território do Vale do Ave e respetivas dinâmicas urbanas, económicas e sociais tem vindo a ser alvo de investigação intensa, fundamentalmente a partir da década de 80 . Destacam-se os trabalhos desenvolvidos por arquitetos e geógrafos, tais como: MagaIhães (1984); Domingues (1986, 2012); Portas (1986); Sá (1986); Domingues e Marques (1987); Marques (1987); Sá e Domingues (2002); Portas, Domingues e Cabral (2003); Silva (2005, 2007, 2010); e Labastida (2013). Destaca-se ainda o trabalho de investigação desenvolvido na Escola de Arquitetura da Universidade do Minho, desde 2001, sobre este território, o qual tem pesquisado formas alternativas de reconhecimento das suas especificidades, como base para a sua transformação potencial (Silva et al, 2017; Silva \& Pereira, 2017). Este artigo integra-se e vem dar continuidade aos estudos precedentes, através da transcrição do espaço do Vale do Ave em som.

No âmbito dos estudos sobre paisagem sonora destaca-se o livro seminal Soundscapes (Schafer, 1993) que cunhou o termo "paisagem sonora" definindo-o como o ambiente sonoro do dia-a-dia com o qual nós vivemos; em Portugal destaca-se o livro Sons e silêncios da paisagem sonora portuguesa (Augusto, 2014). Este artigo, porém, apresenta 
uma investigação inversa às referências anteriores, uma vez que parte do desenho do espaço para a sua transcrição em som. Neste sentido os conceitos de paisagem sonora (sons que nos rodeiam) e o conceito interdependente de sonosfera (relativo à experiência acústica individual da paisagem sonora que nos envolve e invade o nosso corpo sensorial) têm que ser reinterpretados nesta pesquisa. A paisagem sonora exposta é o som, enquanto resultado final do processo de transcrição, e não o objeto inicial de experiência no lugar ou respetivo registo (mapa sonoro), isto é, o som existente na paisagem, como acontece nos trabalhos de investigação anteriormente citados. Os mapas sonoros aqui gerados correspondem às composições musicais resultantes da transcrição.

\section{EXPLORANDO O DESENHO DO SOM}

Durante milénios, utilizou-se o som para cantar, tocar e dançar. Essa foi a primeira música, que se transmitia apenas oralmente. Mas um dia alguém se preocupou em tornar uma dessas músicas permanentemente transmissível, de um modo que não fosse oral, ou seja, em escrevê-la. Não existia, então, método ou instrumento para o fazer. (...) Havia que representá-los através de elementos percetíveis. (Le Corbusier, 2010, p. 32)

A notação musical baseia-se num sistema de escrita que representa composições sonoras e sons num sistema gráfico. As vantagens do sistema gráfico remetem para a possibilidade de permitir que um intérprete execute determinada composição sonora sem a ter ouvido, uma vez que sabe ler o sistema de regras da linguagem apresentada. Da mesma forma,

um plano, um projeto desenhado no papel não é arquitetura, mas meramente uma representação mais ou menos inadequada da arquitetura, comparável a uma partitura. A música necessita de ser desempenhada. Depois o seu conteúdo pode surgir. E este conteúdo é sempre sensível. (Zumptor, Oberli-Turner \& Schelbert, 2006, p. 66)

O sistema de notação gráfica, enquanto representação visual do som, sofreu alterações e evoluções até chegar ao sistema de notação que atualmente é mais utilizado. Este sistema utiliza símbolos que têm como base de suporte uma pauta composta por cinco linhas. O conjunto dos símbolos de cada composição, juntamente com o conjunto das pautas, é chamado de partitura. O elemento básico de composição musical que faz parte do sistema de notação musical é a nota, o símbolo principal que possui as características de duração e altura. No entanto, outras características são representadas nos sistemas de notação, nomeadamente a intensidade, a expressão, entre outros.

O conceito da notação gráfica remete para a adição de informação relativamente à forma como os compositores pretendem que a peça musical seja executada. Seguidamente, faz-se uma síntese de ideias, conceitos e experiências de vários compositores, que optaram por reproduzir as suas ideias e perceções sonoras através de métodos de representação que se afastam dos métodos tradicionais. 
O epitáfio de Seikilos (González de Tobia, 2007) é dos mais antigos exemplos de notação musical ocidental, sendo característico de melodias praticadas na Grécia Antiga e gravadas em lápides. O sistema de representação baseava-se em símbolos e letras, que representavam as notas, acompanhados pelo texto da canção.

Já no século XX, destacam-se: o compositor Krzysztof Penderecki (Hoek, 2007; Meder, 2006), que escreveu Polymorphia (1974) que, como o próprio nome indica, sugere a variação de forma, onde o compositor assume a busca de novas possibilidades sonoras; David Bedford, que utilizou novos modos de composição, por exemplo na sua peça Scientific American piece for John Tilbury, através duma expressão gráfica que utiliza formas e colagens sobre pautas, tendo como objetivo serem interpretadas por crianças e por pessoas que não saibam ler a notação gráfica convencional; e, finalmente, Dick Higgins, que reproduz notações gráficas a partir de tiros de metralhadora sobre uma folha com pautas, reproduzindo várias expressões artísticas e novas conceções de ideias sonoras, como é o caso da sua Symphony No. 357, from The thousand symphonies (1968).

$\mathrm{Na}$ década de 1950, os compositores experimentais questionaram os cânones da representação musical, através da denegação da composição nas cinco linhas, criando formas mais expressivas de notação gráfica, a qual não só ganha valor visual por si, mas estimula a liberdade na interpretação musical.

Conhecido por composições indeterminadas e experimentais, Cornelius Cardew compôs, entre outras obras, Treatise 4 (1963-1967). Composta e desenhada por símbolos e formas geométricas, ou elementos abstratos, que se afastam da notação musical tradicional, a obra é representada por uma partitura composta por gráficos musicais em 193 páginas, onde se encontram os mais diversos símbolos, linhas e formas geométricas e abstratas que se afastam radicalmente da notação tradicional.

John Cage explorou o uso da indeterminação, de forma a dar atenção à subjetividade conferida pelo intérprete, independentemente da forma como está graficamente representado o som. Como refere o autor (1973, p. 10), "deixar os sons serem eles mesmos ao invés de veículos para teorias concebidas pelos homens ou expressões de sentimentos humanos". Fontana Mix ${ }^{5}$ (1958) é uma composição de Cage (Holmes, 2012), onde o desenho e a sobreposição são elementos utilizados para representar o som. Trata-se de uma partitura gráfica composta por várias folhas, das quais umas são transparentes com desenhos de pontos aleatórios, uma possui uma linha reta, outra uma trama ortogonal e as outras têm linhas curvas. Trata-se de sobrepor as imagens de formas diferentes de modo a resultarem imagens gráficas dissemelhantes, criando um sistema de transparências, que tem como intuito funcionar como uma ferramenta de combinações aberta, a partir da qual se determinam correspondências sonoras, ficando o resto a cargo do intérprete.

A peça Poème électronique 6 (1958), de 480 segundos, composta por Edgard Varèse, foi criada com o intuito de projetar uma libertação de sons e associá-la a um novo

\footnotetext{
${ }^{4}$ Retirado de https://www.youtube.com/watch?v=JMzIXxlwuCs

${ }^{5}$ Retirado de https://www.youtube.com/watch?v=05wBPhWD44U

${ }^{6}$ Retirado de https://www.youtube.com/watch?v=R-R3F3ZVbi8
} 
registo gráfico desses mesmos sons. A notação gráfica criada representa um método que é construído por um conjunto de linhas que se assemelham a ondas sonoras. Estas linhas variam entre linhas contínuas e linhas a tracejado.

O compositor Roman Haubenstock-Ramati desenvolveu trabalhos caracterizados pela inovação criativa da notação gráfica, com uma forte relação artística no sentido visual. Das obras que compôs, na experimentação de novos sons e novas formas de o representar, destacam-se Multiple 1 for 2 players (1969), Alone ${ }^{7}$ (1965) e Konstellationen ${ }^{8}$ (1971).

Anestis Logothetis considerava que a nova expressão musical correspondia a representações do som e do ruído polimórficas, e que na experimentação de novas expressões de representação, surgiriam novas variantes e ideias sonoras. Desta forma, alegava que a representação visual tradicional da composição sonora era limitadora e não tinha espaço para a inserção de novas ideias. Além disso, conferia liberdade de execução ao intérprete na leitura dos seus desenhos sonoros permitindo, consequentemente, outro dinamismo e imprevisibilidade à composição sonora. Nas palavras do autor,

o que diferencia fundamentalmente a notação gráfica da notação tradicional é o polimorfismo supramencionado, que permite claramente aos artistas manterem os seus tempos de reação subjetivos. O compositor leva em consideração as divergências dos diferentes atores na composição e espera um certo grau de surpresa pela nova formalização da forma musical em cada performance. ${ }^{9}$

O trabalho desenvolvido sobre a composição Artikulation ${ }^{10}$ (1958), por Rainer Wehinger, é pertinente pela projeção da pontuação gráfica e pela linguagem e sistema de regras que cria. Artikulation caracteriza-se por uma notação gráfica que apresenta os desenhos dos sons executados. Alguns anos depois, Rainer reproduziu um sistema que representava diferentes sons e sonoridades através de símbolos gráficos. Destaca-se, assim, a entrada de um novo elemento no campo da representação gráfica dos sons (os sistemas informáticos) que permite um meio-termo entre a representação do som e a realização. Desta forma, percebe-se uma correlação entre a imagem gráfica e o som reproduzido.

Earl Brown, apesar de ter usado a notação gráfica tradicional, também criou notações gráficas inovadoras, que denominou de "notação tempo" ou "notação proporcional", onde os ritmos eram determinados pelo desenho horizontal dos símbolos, mas sempre com a opção de interpretação flexível. Na composição December ${ }^{11}$ (1952) utiliza métodos gráficos para transparecer o seu sentido da música. A sua experimentação e improvisação demonstraram ser uma base teórica relevante na composição contemporânea.

\footnotetext{
7 Retirado de https://www.youtube.com/watch?v=WpbxxbQcclY

${ }^{8}$ Retirado de https://www.youtube.com/watch?v=Brlfz4WfY2c

${ }_{9}$ Retirado de http://anestislogothetis.musicportal.gr/the_graphic_notation/?lang=en

${ }^{10}$ Retirado de https://www.youtube.com/watch?v=71hNI_skTZQ

"Retirado de https://www.youtube.com/watch?v=WlGkaP4u2cw
} 
Karlheinz Stockhausen desenvolveu um sistema de representação da música ele-

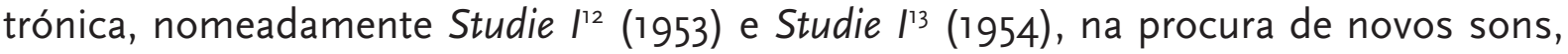
através da reprodução em ferramentas tecnológicas. O autor desenvolve uma nova abordagem para os elementos básicos da música e a sua organização, através de novas experimentações e representações.

Ben Patterson (1934) compôs Duo for voice and a string instrument (1961). O método gráfico utilizado nesta obra consiste num conjunto de símbolos e duas folhas de papel vegetal, nas quais o compositor desenha contornos circulares e retangulares para transmitir as suas ideias sonoras.

Os vários autores apresentados anteriormente quebraram barreiras e colocaram novas questões relacionais entre a notação musical e a arte visual, permitindo, a certo momento, que o próprio registo do som se transformasse e fosse encarado como uma expressão artística visual. Esta nova expressão visual corresponde ao caráter inovador das composições musicais desses autores, contrastantes com os cânones tradicionais. Percebem-se, assim, dinâmicas relacionais entre o compositor enquanto artista sonoro e enquanto artista visual. Para além disso, a ambiguidade da notação musical enquanto arte visual, estimula a liberdade criativa do intérprete, permitindo a reprodução da música com um maior número de componentes variáveis e criando novos estilos de interpretação, que automaticamente produzem musicalidades diferentes.

A partir do momento em que a música apresenta a variabilidade de representações descrita, abre-se a possibilidade de representar o som, segundo diferentes parâmetros. Os vários exemplos de notação gráfica apresentados resultam da necessidade de registar o som, de desenhar o que se ouve e o que se quer que os outros ouçam. A apetência de associar o desenho artístico à representação gráfica do som pode ser projetada na associação desse mesmo desenho à representação do território. Para avançar nesta interseção é relevante agora explorar o processo inverso através da pesquisa de autores que trabalharam a representação sonora do espaço.

\section{EXPLORANDO O DESENHO SONORO DO ESPAÇO}

Além das notações anteriormente referidas, são agora apresentadas e analisadas outras abordagens associadas à representação musical enquanto processo criativo que estão diretamente relacionadas com a representação do espaço. Vários autores abordaram esta interseção e a sua especificidade (Muecke \& Zach, 2007; Ripley, Polo \& Wrigglesworth, 2007), dos quais resultaram ensaios relevantes. Entre outros, ressaltam-se os seguintes autores: Mikesch Muecke e Miriam Zach; Michael Rasbury; Galia Hanoch-Roe; Kourosh Mahvash; Kim Chow-Morris; Tomek Smierzchalski. Dos autores que diretamente contribuíram para a construção dos critérios de correspondência entre som e espaço da nossa metodologia destacam-se Kim Chow-Morris e Galia Hanoch-Roe. É sobre estes apenas que o presente tópico se foca.

\footnotetext{
${ }^{12}$ Retirado de https://www.youtube.com/watch?v=1GoUzk6fQAA

${ }^{13}$ Retirado de https://www.youtube.com/watch?v=_qi4hgT_doo
} 
Kim Chow-Morris, especializada em etnomusicologia, desenvolveu um ensaio sobre os ritmos das ruas, ao qual chama Sounding the structures of the city (2007). Em conjunto com o arquiteto Ian MacBurnie, exploraram a abordagem visual na relação com o som, assim como a interpretação do som através de estruturas visuais da cidade, tendo como referência a cidade de Toronto. Assim, depois de "discutir até certa medida a traduzibilidade de diversos parâmetros da estrutura urbana e da música, decidimos que o fabrico das ruas da cidade em si tornar-se-ia o nosso foco primário" (Chow-Morris, 2007, p. 147). A partir deste enfoque, os autores selecionaram um caminho através de uma subsecção da cidade, "uma vez que o meio sonoro frágil da música existe necessariamente no tempo, e é assim mais facilmente traduzido para um formato linear" (Chow-Morris, 2007, p. 149). Após elaborarem os mapeamentos da cidade, selecionaram a Rua Queen, 501 devido à variabilidade e dinâmica dos acontecimentos que decorrem na sua continuidade. Chow-Morris instintivamente leu os mapeamentos como se fossem uma notação gráfica e através da multiplicidade e da riqueza da rua iniciou o processo de correspondências, onde foram selecionados diversos instrumentos para a representar. Das correspondências efetuadas, pela equipa, destacam-se: a associação da guitarra para as ruas do sul e do piano para as ruas mais estreitas; o aumento da intensidade sonora nos cruzamentos principais da rua. Segundo a autora, a criação de uma composição musical que represente a estrutura da cidade (a rua) reflete um dualismo criativo entre as duas áreas: território e a música.

A experimentação da representação do espaço através de sequências lineares também foi abordada por Hanoch-Roe (2007), por considerar que este tipo de representação adiciona componentes associadas ao movimento, assemelhando-se à dança, música e ao cinema. Segundo a autora, a planta, o corte e a perspetiva são representações visuais estáticas do projeto, revelando limitações no que diz respeito à referência da dimensão temporal - que está associada à ação de caminhar. No desenvolvimento da sua investigação aborda diversos autores, que de uma forma ou de outra, sincronizam o movimento, a representação gráfica e a experimentação no espaço, da qual se destaca a pertinência do estudo realizado por Kevin Lynch.

Kevin Lynch, em conjunto com Appleyard e Myer, em 1964, desenvolveu um sistema de representação de sequências visuais, captadas através de uma viagem de automóvel. Os autores referem que,

o sentido da sequência espacial é semelhante ao da arquitetura de larga escala: a continuidade e insistente fluxo temporal estão a par da música e do cinema. As sensações cinestésicas são como as da dança ou do parque de diversões, embora raramente tão violentas. Essas são todas as artes e situações a partir das quais o designer de autoestradas pode começar a aprender a sua técnica. (Appleyard, Lynch \& Myer, 1964, p. 4)

No exercício que desenvolvem, utilizam diversas simbologias e mapas, onde representam componentes específicos do território: foco de distância; estática dos elementos; texturas; cor dos elementos do percurso; largura da estrada; velocidade; luz; entre outros. 
A análise efetuada revela-se pertinente, na medida em que avança, com uma representação de diferentes pontos de vistas, através da perceção que se tem do lugar ao percorrê-lo, assim como representa as experiências em sequências lineares. Este e outros ensaios permitiram a Hanoch-Roe desenvolver e conceber um sistema de representação do território, enquanto ferramenta de interpretação, produzindo uma sucessão de símbolos, que revelam as características do mesmo, a qual apesar de contrastante é complementar às tradicionais. Os símbolos criados são sobrepostos a uma pauta, para que a leitura do percurso seja realizada e equiparada ao processo de leitura de uma sonoridade, ou seja, ao seguimento de processos no tempo.

A arquitetura é apreciada pelos olhos que veem, pela cabeça que gira, pelas pernas que caminham. A arquitetura não é um fenómeno sincrónico, mas sucessivo, feito de espetáculos, que se juntam uns aos outros, e seguindo-se no tempo e no espaço, como, de resto, o faz a música. (Le Corbusier, 2010, p. 95)

A representação referida caracteriza o percurso enquanto dimensão transversal às estações do ano, ao meio ambiente, às direções a partir do caminho, ao odor, aos estímulos auditivos, entre outros. Na verificação da inexistência de um sistema de representações que interpenetre os dois sistemas de representação (do território e da música), o trabalho de Hanoch-Roe dá pistas para a criação de uma linguagem gráfica comum que represente simultaneamente a interpretação do território e a composição sonora, a qual é aprofundada na segunda parte deste artigo.

\section{Metodologia de TRANSCRIÇÃo do ESPAÇO EM SOM}

Este trabalho tem como principais objetivos criar uma linguagem comum entre a representação do território e a representação sonora, enquanto vínculo intermédio; criar uma metodologia de transcrição, passível de ser aplicada a outro território; produzir um formato de representação do território (a composição sonora) que adicione e complemente informação aos formatos convencionais; originar a possibilidade de ouvir a sonoridade do território, que resulta das especificidades da sua composição espacial e da experiência vivida do observador; e finalmente estimular a interdisciplinaridade, de forma a dar impulsos a novas leituras sobre o território e sobre a composição musical.

As questões de investigação centrais são: como criar uma linguagem comum, que simultaneamente represente o espaço duma amostra de território e seja passível de ser uma notação gráfica sonora? De que forma é que as estruturas e formas urbanas específicas se revelam em apresentações sonoras diferenciadas? Como se processa a transcrição de elementos espaciais, que compõem o território, para elementos que se organizam no tempo, os sons?

$\mathrm{Na}$ procura de resposta a estas questões desenvolve-se seguidamente a metodologia que levou à criação da linguagem comum, estruturada em quatro pontos: a estratégia de transcrição; a gramática; o abecedário; e o método de aplicação, exemplificado numa fração do percurso "entre Brito e Silvares". Na transversalidade do trabalho de 
investigação realizado, os parâmetros explorados possuem uma ambivalência linguística, ou seja, desenvolveu-se uma linguagem gráfica que representa simultaneamente o território em estudo e o som.

\section{A eSTRATÉgia DE TRANSCRIÇÃo}

Como criar uma linguagem comum, que simultaneamente represente o espaço duma amostra de território e seja passivel de ser uma notação gráfica sonora? Cedo se entendeu a impossibilidade de a notação musical convencional (a pauta) representar o território, uma vez que esta usa um sistema de símbolos que apenas correspondem ao som, sendo assim unilaterais. O primeiro desafio da linguagem a ser criada estabelecia-se na necessidade de esta ser bilateral, ou seja, ser o "entre" o espaço e o som, o vínculo espaço-som.

Se o território possui representações gráficas que o apresentam e a música possui sistemas gráficos que a expressam, significa que ambos possuem uma forma passível de ser partilhada, a representação gráfica. Esta particularidade de ambos revela a pertinência de criar uma representação gráfica que apresente o território e ao mesmo tempo seja uma notação gráfica da sonoridade que lhe corresponde.

A palavra transcrição significa "ato ou efeito de transcrever; reprodução de um texto escrito; registo; representação das letras ou caracteres de um sistema de escrita pelos de outro sistema de escrita"14. A palavra transcrição tem origem no verbo latino transcribere, composto por "trans" que significa além e "scribere" que significa escrever ou compor'15. "Transcrição" significa, nesta investigação, o transpor de informação de uma linguagem ${ }^{16}$ para outra, isto é, transcrever enquanto ato de interpretação. Para isso, é necessário criar vínculos e pontes de afinidade entre as duas áreas. Isto é, um sistema de regras que permita a escrita - neste caso a transcrição - entre dois elementos de representação.

A composição do território e a composição musical partilham elementos que estão na base da sua caracterização, tais como a altura, proporção, peso, densidade, distância, ritmo, silêncio, melodia, entre outros. São estes elementos que thes conferem forma e definem a particularidade de cada espaço ou som. A partir destes elementos, o território organiza-se no espaço e as sonoridades no tempo.

Como referido na introdução, o processo de experimentação é aplicado a duas amostras do território do Vale do Ave, concebendo uma nova aproximação a este território, catalisada pelas dissonâncias associadas à multiplicidade deste lugar.

A seleção de duas amostras justifica-se nas suas especificidades e desdobra-se na sua dissonância compositiva, correspondente a dois modelos de povoamento aos quais

\footnotetext{
14 Ver Dicionário de língua portuguesa (2013), Porto: Porto Editora.

15 Ver Dicionário online de Latim, Glosbe, disponível em https://pt.glosbe.com/la/pt/

${ }^{16}$ Linguagem: qualquer sistema ou conjunto de sinais convencionais, fonéticos ou visuais, que servem para expressão dos pensamentos e sentimentos; qualquer sistema de símbolos instituídos com signos; código. Ver Dicionário de língua portuguesa (2013). Porto: Porto Editora.
} 
serão aplicados os mesmos critérios de análise. A pertinência em explorar duas amostras, com sistemas morfológicos diferentes está relacionada com o objetivo de provar a hipótese inicial, da vinculação entre espaço e som. De que forma é que as suas estruturas e formas urbanas específicas se revelam em apresentações sonoras diferenciadas?

Diz-me (já que és tão sensível aos efeitos da arquitetura), não reparaste, ao vaguear por esta cidade, que entre os edifícios pela qual é populada, alguns são mudos; outros falam; e outros, por fim - e estes são os mais raros cantam? (Valery, 1956, p. 82)

Qual o primeiro vínculo encontrado? O percurso tornou-se o recurso dos ensaios de interseção, pois assim como um percurso ao ser percorrido é uma sucessão linear de acontecimentos no espaço, vividos no tempo, uma sonoridade ao ser ouvida é uma sucessão linear de acontecimentos no tempo, vividos no espaço. Assim o tempo é o primeiro vínculo, uma vez que tanto o caminhar no espaço, como a música, são processos lineares no tempo. Como refere Hanoch-Roe (2007, p. 77) "as sequências lineares incorporam noções de movimento, perceção móvel e ritmo, que tornam a sua experiência semelhante à de outras artes como a música, dança e cinema". O processo de transcrição adotou, assim, como análise focal a interpretação de dois percursos (Figuras 3 e 4), cada um encontrado pela ação de percorrer o espaço de cada amostra selecionada.

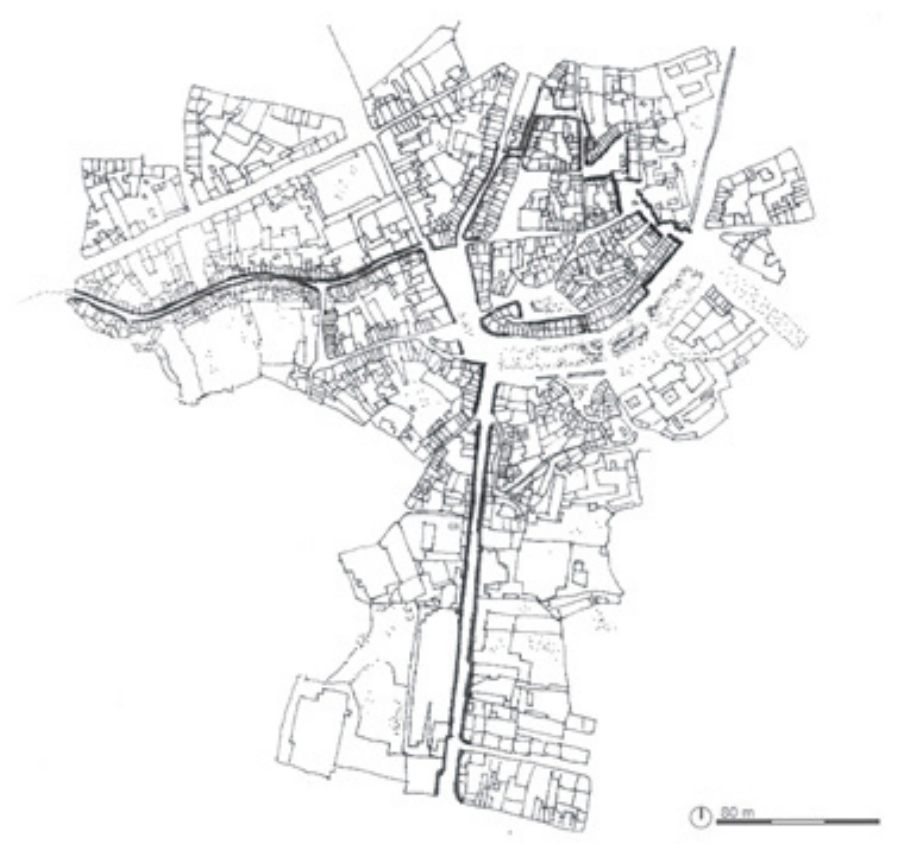

Figura 3: O percurso selecionado no centro de Guimarães inclui a Rua D. João I, O Largo do Toural, a Rua de S. António, a Rua Vale Donas, Rua João Lopes de Faria, Praça Santiago, Largo da Oliveira, Alameda de S. Dâmaso, Largo da Condessa do Juncal, Largo 25 de Abril e termina no fim da Avenida D. Afonso 


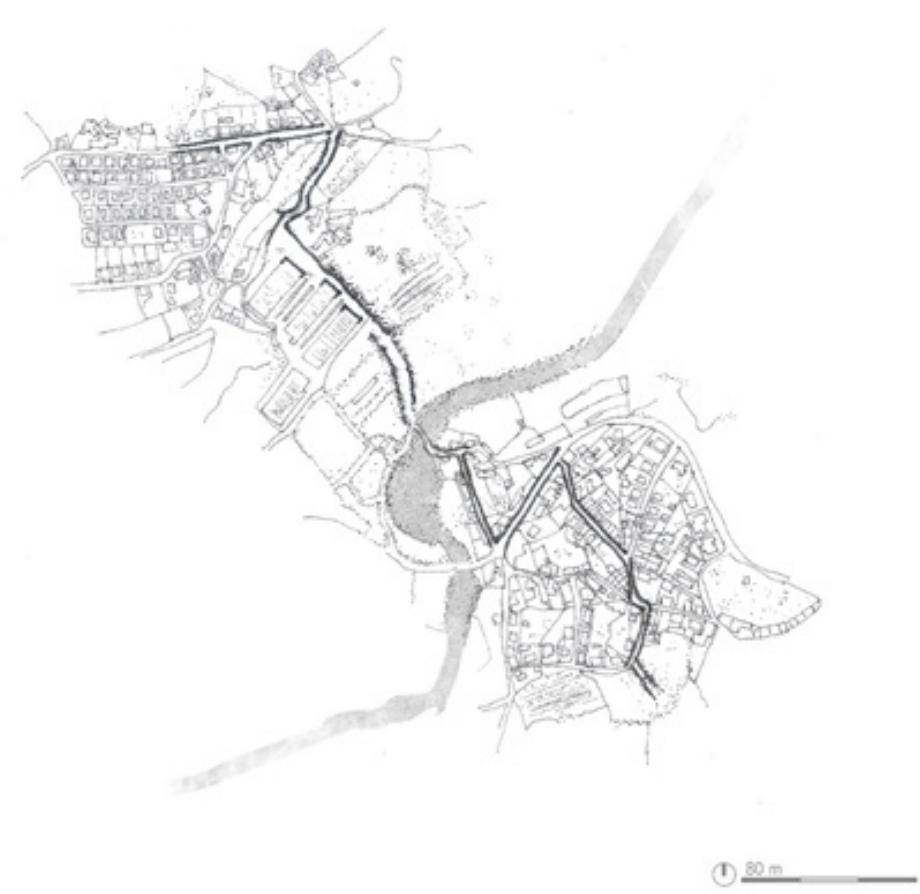

\footnotetext{
Figura 4: O percurso selecionado "entre Brito e Silvares" inicia na Rua do Rio Ave, Rua da Liberdade, Travessa das Bouças, atravessa o Rio até chegar à Rua dos Moinhos, continua pela Avenida 25 de Abril, Rua $1^{\circ}$ de Maio, Rua dos Moleiros e termina numa parcela agrícola
}

A escolha do percurso como princípio do método de transcrição revela-se fulcral em dois fatores transversais à investigação: o primeiro remete para o facto de permitir um olhar específico sobre o território, uma vez que o observador possui um papel ativo no processo, pois a recolha de informação é feita a partir do ato de percorrer o lugar in situ; o segundo fator confere "tempo" ao espaço, uma vez que o percurso é percorrido ao longo de um determinado intervalo de tempo; enfatizando-se assim que "o olho parado não vê" (Pimenta, 1993, p. 4), a complexidade do lugar-território.

Ambos os percursos partilham um princípio de seleção que explora diferentes articulações e diferentes características de composição com o objetivo de potencializar a transcrição e a sua abrangência. A seleção dos percursos baseia-se na diversidade, mas também na especificidade, na identificação de tipos de morfologias específicas que, na generalidade, são a base da composição da forma do território.

\section{A gRAMÁticA}

Como se processa a transcrição de elementos espaciais, que compõem o território, para elementos que se organizam no tempo, os sons? Se se pretende a transcrição de uma composição no espaço para uma correspondente composição no tempo é necessária uma linguagem de termos e de analogias para a poder transcrever. Isto é, um sistema de regras que permita a escrita - neste caso a transcrição - entre dois elementos de representação e apresentação, e que vá para além das regras de construção de cada área em estudo. Assim, a transcrição apoia-se numa gramática - um sistema de regras - de forma a conseguir a passagem de informação entre a organização do espaço e a composição 
musical. A gramática define-se num sistema de regras, as quais operativamente permutam informação entre a organização do espaço e a composição sonora (Figura 5).

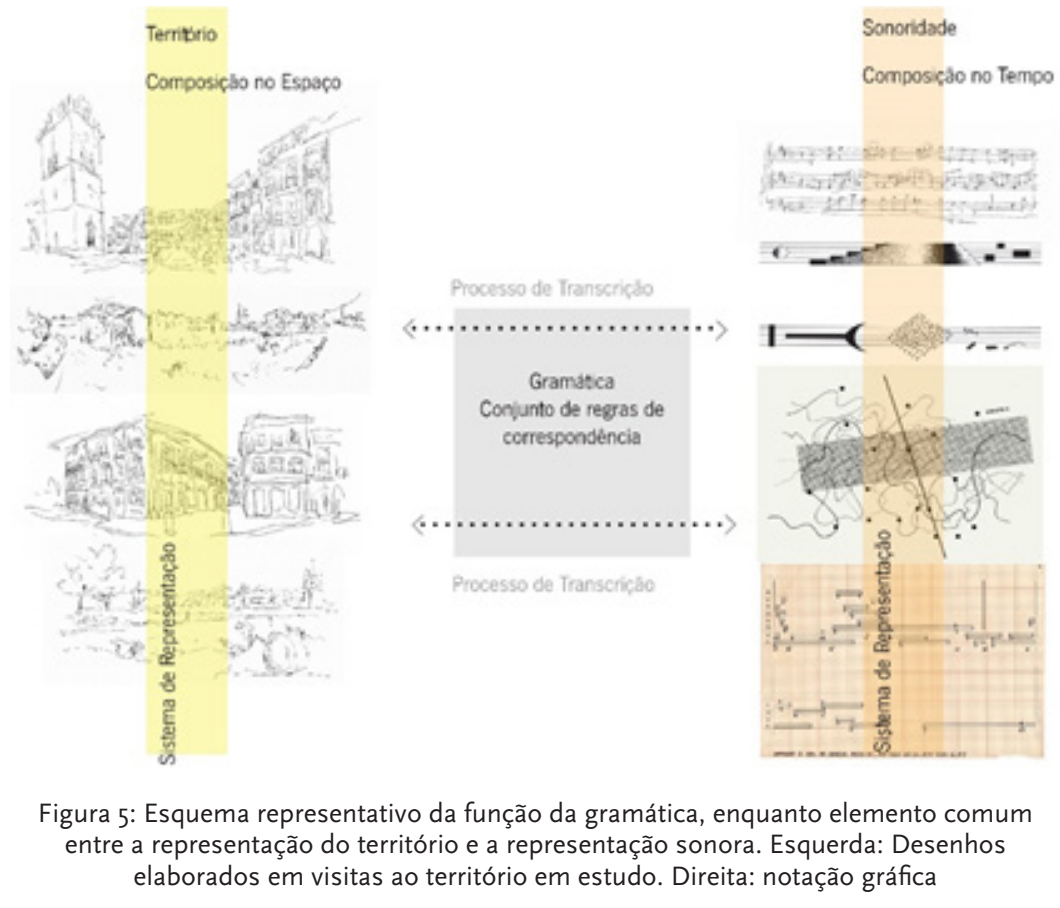

Com as análises efetuadas ao território em estudo e às unidades-base da sua composição, isolaram-se os elementos relativos à composição e à expressão do território e à composição sonora. Surgiram, então, diferentes elementos de correspondência, viáveis de relação, que permitem a transcrição e ao mesmo tempo constroem a gramática e as suas regras. Distinguiram-se dois grupos de correspondência: os elementos de organização/composição e a particularidade/expressão.

O grupo de correspondência da organização e composição remete para as características e variação dos elementos constituintes no território e na sonoridade, os elementos que lhe conferem forma. Assim, fazem-se corresponder os elementos organizacionais do território aos elementos compositivos das sonoridades. A particularidade e a expressão estão relacionadas com a organização e a articulação de elementos anteriormente referidos, isto é, o conjunto de particularidades que podem variar com as características de cada território e com a interpretação dada na execução de diferentes sonoridades.

Para delinear a gramática é necessário assim estabelecer os parâmetros de correspondência, entre os elementos constituintes do território e os elementos estruturais de uma composição sonora, encontrando assim os vínculos "entre". Destes selecionam-se, a título de exemplo, a que elementos sonoros correspondem os volumes e espaços intersticiais do território? Consideram-se espaços intersticiais, os espaços com ausência de construção vertical, ou seja, praças, continuidades de ruas, jardins, parcelas agrícolas, entre outros. São espaços definidos entre os elementos de estrutura vertical. Esta experiência remete para uma decomposição dos elementos que caracterizam o espaço intersticial entre os alçados que acompanham o percurso. Estes espaços não são considerados 
vazios, no contexto desta investigação, porque possuem conteúdo específico (Zardini, 2005). A apresentação destes espaços remete para a representação dos espaços intersticiais, que resulta na ausência de estrutura sonora.

Um percurso urbano é conformado por "volumes" construídos, como edifícios, muros, etc., e por "espaços intersticiais", como praças, jardins, parcelas agrícolas, espaços 'entre' volumes. Assim, fez-se corresponder (Figura 6) o "volume" ao "som" e os "espaços intersticiais" à "ausência de estrutura sonora" (Leite, 2014, pp. 149-151). Para que a representação manifestasse a musicalidade dos espaços intersticiais, considerou-se tanto a vegetação que estes possuem como os planos que os encerram a uma maior distância do observador, como é o caso do segundo plano, considerado no acompanhamento (Leite, 2014, pp. 145-148).

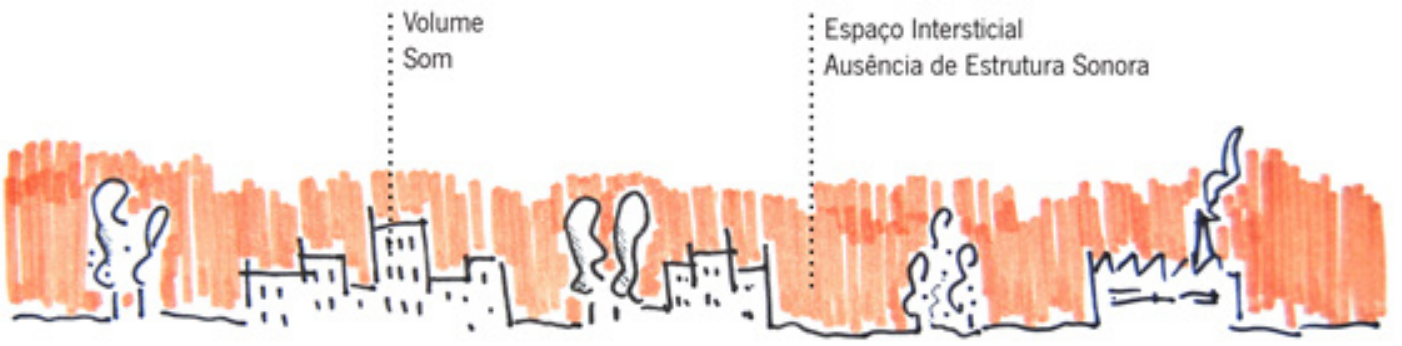

Figura 6: Desenho esquemático da correspondência de elementos estruturais do território, neste caso volume e espaço intersticial, com elementos compositivos sonoros, som e ausência de estrutura sonora

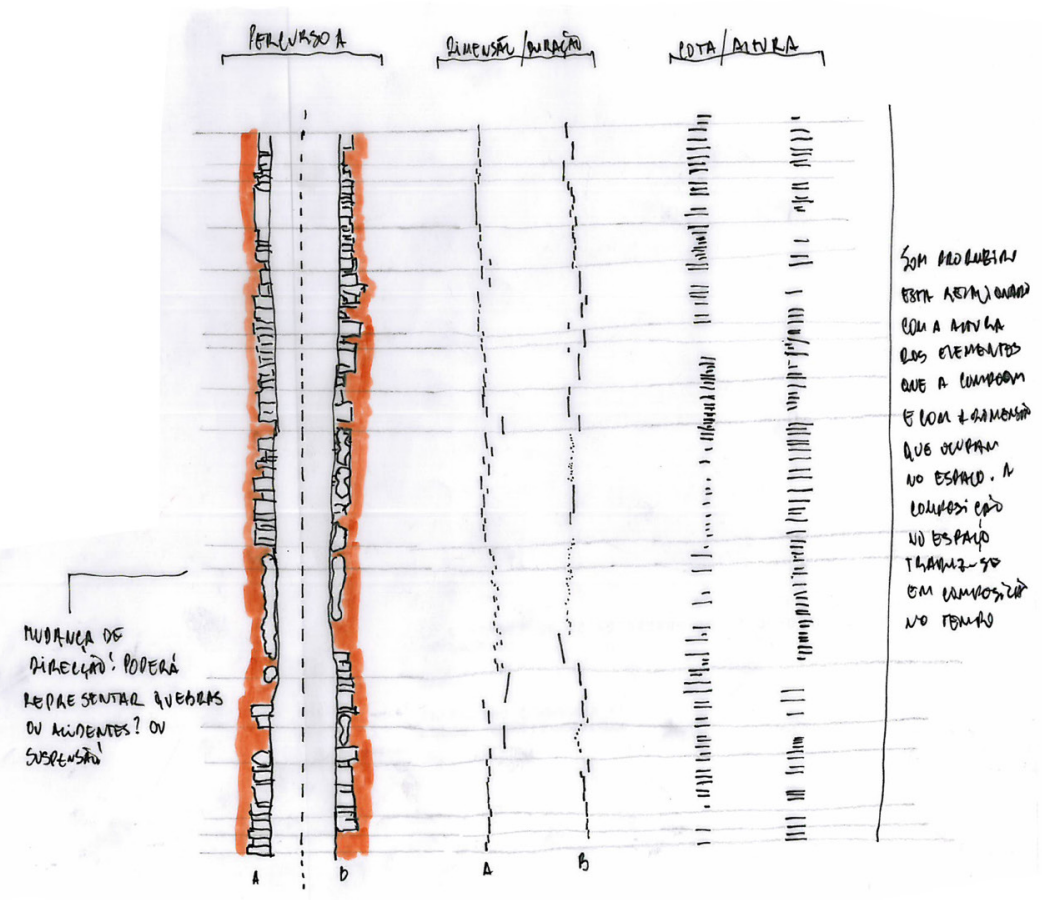

Figura 7: Alçados direito e esquerdo do percurso e ensaios de decomposição correspondentes 
Os vínculos encontrados são aplicados aos dois alçados do percurso. O percurso é composto por duas frentes de informação, o lado direito e o lado esquerdo, que organizam e acompanham o espaço percorrido, cada um com as suas especificidades. A transcrição dos alçados corresponde às dinâmicas de stereo. O stereo caracteriza-se por uma representação tridimensional do som que é reproduzido por duas fontes de áudio diferentes e sincronizadas. O objetivo é conferir tridimensionalidade ao som, através da distribuição dos mesmos em tempo real, proporcionando a sensação espacial. Assim, cada percurso tem dois alçados a serem transcritos, resultando em duas sonoridades, que correspondem a dois canais de áudio. Os dois alçados, sincronizados, acordam o seu contributo para a construção de uma composição sonora, de forma a reproduzir a atmosfera espacial do espaço (Figura 7).

\section{O ABECEDÁRIO}

Uma vez definidos os parâmetros de correspondência, é necessário criar uma representação gráfica dos elementos do território e atribuir-lhes um som, ou seja, desenhar as "letras" do território e dar-lhe a sua fonética. Da mesma forma que o "a" corresponde a um som, permitindo a sua transmissão, também os elementos gráficos desenhados, correspondem a uma sonoridade (Figura 8). Das "letras" sistematizadas (Leite, 2014, pp. 180-181) seleciona-se como exemplo a trama preta, a qual é utilizada para a representação de um volume edificado e corresponde a um som mais denso, enquanto que a trama de pontos representa árvores e corresponde a uma sonoridade mais fluida. Justifica-se este critério de representação tendo em conta a porosidade sonora das árvores em contraponto com a falta de porosidade dos volumes construídos. Pretende-se que a diferenciação, nas sonoridades e timbres reproduzidos, permita identificar os diferentes elementos que compõem o território, assim como as consequentes correspondências.

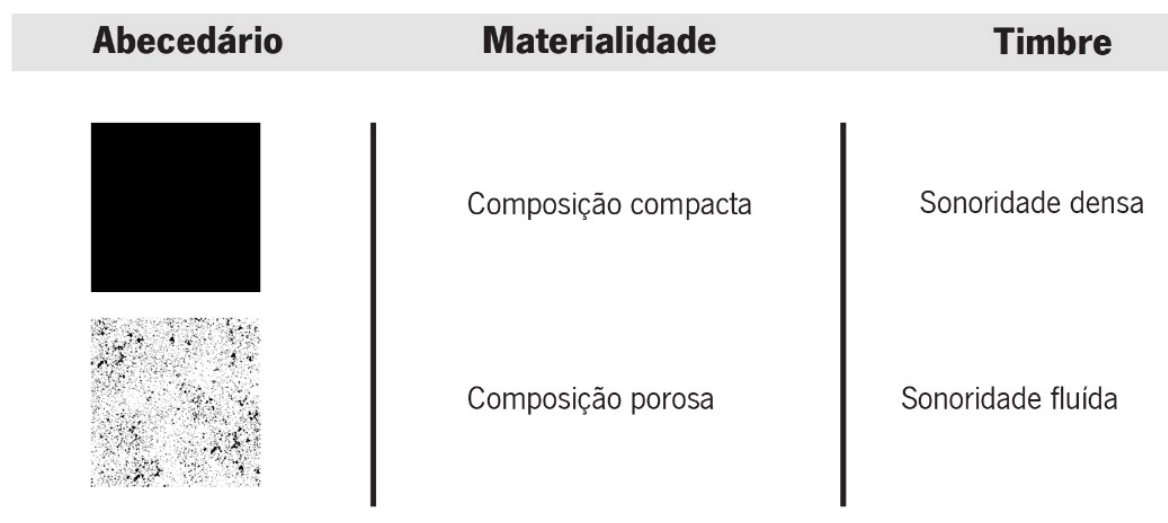

Figura 8: Exemplo do sistema de representação dos elementos transcritos. Relação entre composição compacta e porosa e respetiva sonoridade correspondente (aqui descrita textualmente)

O abecedário é o conjunto de elementos-base da linguagem comum entre espaço e som. Como as letras formam palavras, que formam frases, também este abecedário permite formar as frases, parágrafos, e finalmente o 'texto' - notação gráfica ambivalente 
-, simultaneamente passível de representar o espaço e o som. Em síntese, o abecedário é "a escrita e o som," o qual materializa a representação (visual-sonora) da gramática de correspondências definida e permite a transcrição das amostras de território selecionadas, através da metodologia de transcrição, seguidamente explicitada.

\section{O MÉTODO DE APLICAÇÃO DA TRANSCRIÇÃO}

Encontrados os parâmetros de correspondência e a sua escrita espácio-sonora, define-se o método de transcrição, ou seja, a sistematização da aplicação da gramática e do abecedário. Este método é composto por três categorias: o alçado, a planta e a experiência vivida no lugar. Cada uma destas categorias é subdividida em estratos que representam diferentes pontos de vista e camadas do território. A cada um dos estratos é aplicado o processo de transcrição, onde são usadas as regras da gramática e as representações do abecedário já referido. Da transcrição de cada estrato, resulta uma notação gráfica que representa uma especificidade espácio-sonora.

Qual a necessidade de desdobrar a análise do território em vários estratos? Cada um corresponde a uma informação diferente, não só relativa ao lugar, mas também relativa a uma característica da composição sonora; da mesma forma, os estratos juntos e sobrepostos compõem as sonoridades do percurso. Quantas mais variantes são consideradas, mais fiel e articulada é a composição sonora com o lugar, dado que são transcritas diferentes camadas de complexidade. Como refere James Corner,

existe uma duração da experiência, um desenrolar serialista dos antes e depois. Tal como uma paisagem não pode ser reduzida espacialmente a um único ponto de vista, não pode ser congelada num único momento do tempo. A geografia de um sítio torna-se conhecida para nós através de uma acumulação de fragmentos, devaneios e incidentes que sedimentam significado, 'acumulando-se' ao longo do tempo. Onde, quando e como alguém experiencia uma paisagem origina qualquer significado que deriva da mesma. (Corner, 1992, pp. 147-148)

No exemplo da Figura 9, ilustra-se uma fração do percurso "entre Brito e Silvares", cujo alçado esquerdo é conformado por parcelas agrícolas, enquanto que o direito é conformado por parcelas habitacionais ${ }^{17}$. Do exterior para o interior visualiza-se o desenho dos alçados e o correspondente desdobramento dos estratos da notação gráfica espácio-sonora.

\footnotetext{
17 Dada a complexidade do processo de transcrição, optou-se por exemplificar o desdobramento aplicado apenas à categoria dos alçados; ver Leite, 2014, pp. 158-167, para estudar a categoria planta, e Leite, 2014, pp 168-175, para a categoria experiência vivida.
} 


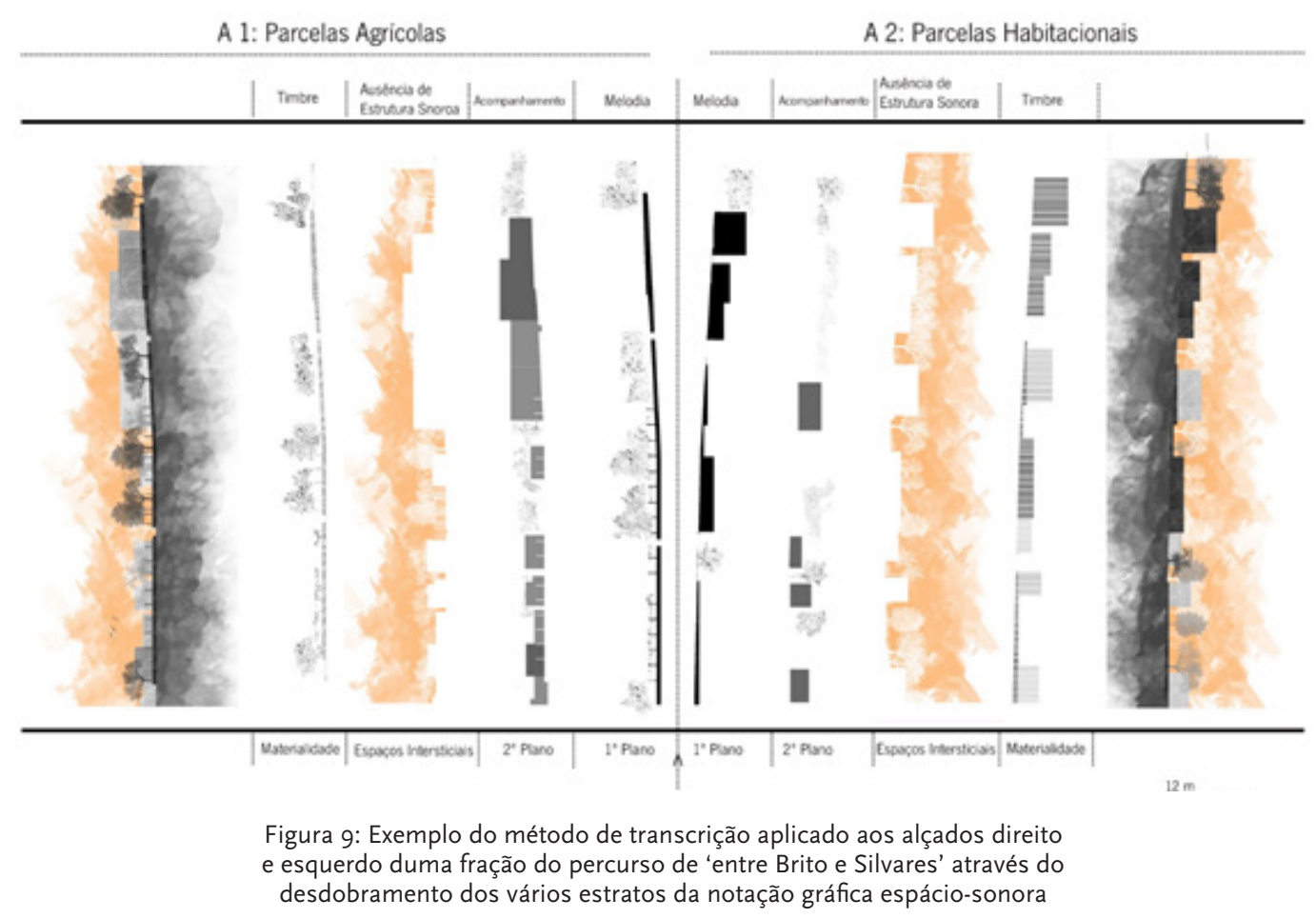

De que forma as decomposições dos suportes de representação do território permitem construir uma composição sonora? Após o estudo das três categorias de análise - 0 alçado, a planta e a experiência vivida -, é aplicada a metodologia de transcrição, onde são usadas as regras da gramática construída. A transcrição é aplicada a cada estrato de cada categoria, resultando uma notação gráfica que lhe é correspondente.

\section{ANÁLISE dos RESULTADOS}

$\mathrm{Na}$ globalidade, o processo de transcrição analisa diferentes camadas compositivas do território e faz uma desconstrução até chegar a uma simbologia/notação que o represente. Ao mesmo tempo, essa simbologia é uma representação gráfica da sonoridade resultante da composição do percurso.

Considera-se pertinente referir que a análise efetuada ao território e a reprodução dos desenhos dependem do observador e do momento em que caminhou pelo percurso. Desta forma, a análise da representação efetuada pode variar com as estações do ano, deixando as árvores com massas de folhas mais ou menos compactas, assim como a transformação do lugar ao longo do tempo, entre outros fatores.

Os alçados são realizados de acordo com uma análise e experiência in situ, por isso mesmo, os desenhos e a transcrição não são eternizados, são apensas representações de um tempo específico.

A notação gráfica, que resulta do desdobramento, representa a informação a ser executada em sonoridades parciais. Após a sua transcrição é possível executar e reproduzir as sonoridades de cada estrato, sendo que a reprodução simultânea de todos os estratos corresponde à composição sonora do percurso transcrito, resultando na síntese 
espácio-sonora ${ }^{18}$ do percurso - no "entre" espaço percorrido e o som correspondente. Cada percurso tem uma composição sonora de 25 minutos, resultado do conjunto das cinco frações interpretadas, com cinco minutos de duração. Assim no total, para os dois percursos, temos uma composição musical de 50 minutos de duração.

\section{Conclusões}

A investigação, fundamentada no processo de transcrição da representação visual do território em representação sonora, ao abordar tanto uma amostra do território difuso ("entre Brito e Silvares"), como uma do território compacto (centro de Guimarães), criou uma metodologia abrangente, possibilitando a sua aplicação a outros lugares do urbano contemporâneo e a sua correspondente transcrição sonora. A sua aplicação a estas amostras distintas permitiu comprovar a hipótese inicialmente colocada, ou seja, a existência de um vínculo entre a composição espacial e a composição sonora.

Esta pesquisa apresenta-se como ferramenta de trabalho operativa que permite o conhecimento do território pela exploração das suas sonoridades, despertando a sensibilização e a perceção dos espaços através de paisagens sonoras criadas a partir dos percursos percorridos, que por sua vez são narrados em sons articulados. As composições sonoras resultam da transcrição dos elementos físicos e característicos de determinado espaço proporcionando uma diferente amplitude no estudo e aproximação ao território.

Este processo de transcrição permite, por sua vez, vir a explorar diferentes variantes de aplicação das sonoridades criadas, nomeadamente a criação de representações ambivalentes através da leitura espacial e musical, tal como mapas sonoros. Os mapas são ferramentas que ajudam na compreensão do território, da paisagem, das pessoas, da cultura, da história, e são também arquivos sonoros do território e da sua evolução no tempo, assim como ferramentas interativas na relação da representação gráfica do território, em simultâneo com a sonoridade que dele resulta.

O processo de entendimento de um espaço, através da transcriação da sua morfologia em composições sonoras gera uma representação do território, que funciona como complemento de informação a outros modos de representação do território (planta, corte, modelo 3D, maqueta, fotografia, entre outros), contribuindo, desta forma, para a perceção do território, para além da prática visual - criando uma nova representação do espaço baseada numa estrutura elementar diferente, o som no tempo.

A pertinência desta investigação, enquanto processo de experimentação em aberto, revela-se na criação de uma metodologia aplicável a outros percursos em outras amostras territoriais. Isto é, a metodologia de transcrição é passível de ser aplicada noutro lugar, que possivelmente possa conter componentes que não foram referidos na presente experiência da construção do processo de transcrição; porque cada lugar é um lugar. Por isso mesmo, considera-se que a gramática e a metodologia de transcrição possam ser um ponto de partida para a adição de conteúdos de novos componentes

\footnotetext{
${ }^{18}$ Para ouvir duas das composições sonoras resultantes da transcrição consultar: http://youtu.be/8GpEyrOPb8o (excerto do percurso no centro de Guimarães) e http://youtu.be/hKpISPeg4A4 (excerto do percurso "entre Brito e Silvares").
} 
detetados em outros lugares e por outros observadores. Há igualmente que ressaltar que o método de transcrição proposto abre um novo campo de possibilidades ao nível da composição musical.

Interessa desta forma salientar, que dependendo da escala de aproximação ao lugar, podem vir a ser integrados novos parâmetros de correspondência, como por exemplo: caraterísticas específicas quer dos espaços intersticiais, quer da arquitetura dos edifícios; a sombra e a luz; a transformação do território ao longo do tempo; o rés do chão, na sua relação articuladora entre espaço público e espaço privado, etc. Ver o espaço através do ouvir continua assim em aberto, para ouvir outros lugares e assim vê-los.

O ouvinte, que aprenda a linguagem proposta, ao escutar uma sonoridade de um percurso, consegue criar uma imagem mental do lugar, sem nunca o ter percorrido. Inversamente, ao percorrer o território, o observador consegue reproduzir uma sonoridade mental, que a sua transcrição pode conceber.

O presente processo de experimentação resulta do devir entre o território e o seu registo sonoro. É no "entre" espaço/som, desenhar/anotar, ver/ouvir, que este projeto explora o potencial incerto da aprendizagem (inter)disciplinar.

\section{REFERÊNCIAS BIBLIOGRÁFICAS}

Augusto, C. A. (2014). Sons e silêncios da paisagem sonora portuguesa. Lisboa: Fundação Francisco Manuel dos Santos.

Appleyard, D., Lynch, K. \& Myer, J. (1964). The view from the road. Cambridge, Massachusetts: The MIT Press.

Cage, J. (1973). Silence: lectures and writings. Middletown: Wesleyan University Press.

Chow-Morris, K. (2007). Rhythm of the streets: sounding the structures of the city. In M. Muecke \& M. Zach (Eds.), Resonance, essays on the intersection of music and architecture (pp. 145-168). Ames, Berlin, Gainesville, Tokyo: Culicidae Architectural Press.

Corner, J. (1992). Representation and the landscape. In S. Swaffield (Ed.), Theory in landscape architecture (pp. 144-165). Philadelphia: University of Pennsylvania Press.

Domingues, A. (1986). Economia e espaço rural. Cadernos do Noroeste, 39-65.

Domingues, A. \& Marques, T. (1987). Produção industrial, reprodução social e território - Materiais para uma tentativa de abordagem do Médio Ave [Industrial production, social reproduction and territory Materials for an attempt of approaching the Médio Ave]. Revista Crítica de Ciências Sociais, 22, 125-142.

Domingues, A. (2012). Vida no campo. Porto: Dafne Editora.

González de Tobia, A. M. (2007). Lenguaje, discurso y civilización: de Grecia a la modernidade. La Plata: Universidad Nacional de La Plata.

Hanoch-Roe, G. (2007). Scoring the path: linear sequences in music and space. In M. Muecke \& M. Zach (Eds.), Resonance, essays on the intersection of music and architecture (pp. 77-144). Ames, Berlin, Gainesville, Tokyo: Culicidae Architectural Press.

Hoek D. J. (2007). Analyses of nineteenth and twentieth-century music. Lanham, Maryland, Toronto e Oxford: Scarecrow Press. 
Holmes, T. (2012). Electronic and experimental music. Technology, music, and culture. Nova lorque: Routledge.

Labastida, M. (2013). El paisaje próximo: fragmentos del Vale do Ave. Tese de Doutoramento, Universidade do Minho, Guimarães, Portugal. Retirado de http://hdl.handle.net/1822/27185

Le Corbusier (2010). O modulor, modulor 2. Lisboa: Antígona, Orfeu Negro.

Leite, E. (2014). Transcrição do território em som. Processo de experimentação aplicado a duas amostras do Vale do Ave. Tese de Mestrado Integrado em Arquitectura, Universidade do Minho, Guimarães, Portugal. Retirado de http://hdl.handle.net/1822/34516

Magalhães, M. (1984). A pluriactividade no Vale do Ave. Porto: CCRN.

Marques, T. (1987). Sistema produtivo industrial e território - um estudo da têxtil em Guimarães. Tese de Mestrado, Universidade de Lisboa, Lisboa, Portugal.

Meder, R. (2006). A study of Krzysztof Penderecki's "Credo": how it exemplifies his compositional style at the end of the 2oth century. Urbana-Champaign: University of Illinois.

Muecke, M. \& Zach, M. (Eds.) (2007). Resonance, essays on the intersection of music and architecture. Ames: Culicidae Press, LLC.

Pimenta, E. (1993). Arquitetura virtual. Londres: ASA Art and Technology.

Portas, N. (1986). Modelo territorial e intervenção no Médio Ave. Sociedade e Território, 5, 8-13.

Portas, N., Domingues, A. \& Cabral, J. (2003). Politicas urbanas, tendências, estratégias, oportunidades. Lisboa: Fundação Calouste Gulbenkian.

Ripley, C., Polo, M. \& Wrigglesworth, A. (Eds.) (2007). In the place as sound: architecture, music, acoustics. Newcastle: Cambridge Scholars Publishing.

Sá, M. (1986). O Médio Ave. Porto: Escola Superior de Belas-Artes do Porto.

Sá, M. \& Domingues, A. (2002). Cidade difusa do Noroeste Peninsular. Volume II. CEFA. Porto: FAUP.

Schafer, M. R. (1993). The soundscape: our sonic environment and the tuning of the world. Rochester, Vermont: Destiny Books.

Silva, C. M. F. (2005). O difuso no Vale do Ave. Tese de mestrado, FAUP, Porto, Portugal.

Silva, C. (2007). Saber ver o difuso no Vale do Ave. In 1st International Conference of Young Urban Researchers. Lisboa: ISCTE. Refereed Conference Paper. Retirado de https://tinyurl.com/y6vzfzvs

Silva, C. (2010). Beyond buildings and roads: an approach to the diffuse territory of Vale do Ave. In B. Pelucca (Ed.), Viaggio Portogallo. Journey to Portugal. Dentro e Fuori i Territori dell'Architecttura. Inside and Outside the Territories of Architecture. (pp. 43-49). Roma: Aracne Editrice.

Silva, C. (2011). Architecture as expanded field. The International Journal of the Constructed Environment, 1(3), 55-70. doi: 10.18848/2154-8587/CGP/vo1io3/37491

Silva, C. F., Labastida, M., Oliveira, I., Carlos, R., Riso, V. \& Pereira, D. D. (2017). On being with-it: experiências pedagógicas sobre território na EAUM. Retirado de http://onbeingwithit.pt/pt/ 
Silva, C. F. \& Pereira, D. D. (Eds.) (2017). On being with-it: Diálogo prospetivo sobre a experiência de aprendizagem através do território / On being with-it: A forward-looking dialogue on the experience of learning through territory. Guimarães: Universidade do Minho. Laboratório de Paisagens, Património e Território - Lab2PT.

Valéry, P. (1956). Eupalinos or the architect. In J. Mathews (Ed.), Dialogues (pp. 63-150). Nova lorque: Pantheon Books.

Zardini, M. (2005). De la "ciudad que sube" al paisaje que avanza. In I. Solà-Morales \& X. Costa (Eds.), Metrópolis (pp. 205-212). Barcelona: Gustavo Gili.

Zumthor, P., Oberli-Turner, M. \& Schelbert, C. (2006). Thinking architecture. Boston: Birkhauser.

\section{NOTAS BIOGRÁFICAS}

Cidália Ferreira Silva é Professora Auxiliar na Escola de Arquitetura da Universidade do Minho e membro integrada do Lab2PT. Desenvolve investigação sobre a questão do tempo aplicada aos lugares contemporâneos e à pesquisa sobre metodologias de investigação que integrem a incerteza no processo criativo. É editora do The International Journal of the Constructed Environment.

E-mail: cidalia@arquitectura.uminho.pt

Morada: Escola de Arquitetura (EA), Campus de Azurém, 4800-058 Guimarães (Portugal)

Eugénia Aguiar Leite é arquiteta na empresa Galbilec e responsável criativa do atelier REarquiteturas. Investiga a correlação entre a arquitetura e a música, nomeadamente através da exploração dos processos de transcrição entre o espaço e o som, tendo neste campo apresentado publicamente o seu trabalho em seminários e exposições interdisciplinares como o "Seminário Territórios Sociedades e Culturas", o "I Colóquio de Psicofisiologia Musical", e a exposição Emerging Art Now.

E-mail: eugeniaaleite@gmail.com

Morada: REarquiteturas, Rua das Doze Casas n.182, 4000-193 Porto (Portugal)

* Submetido: 30-11-2017

* Aceite: 15-02-2018 